\title{
Testing Models of Trade-Off Contrast in Pairwise Choice
}

\author{
Douglas H. Wedell \\ University of South Carolina
}

\begin{abstract}
In three experiments, students completed sets of three pairwise choices in each of several domains. The first two pairs in each set were contextual pairs, and the third was the target pair. Context was manipulated by widening the range of values on one dimension and narrowing it on the second dimension. Consistent with previous research, participants on target trials more often chose the alternative whose poorer value was on the widened dimension. Four models explained this effect as (a) decreased weighting of the wide dimension, (b) contextual shift in values, (c) a tendency to equalize responses, or (d) a tendency to add value based on dominance relationships. Path models provided evidence against weight change and response equalization, and manipulation of dominance did not reduce the effect. Results supported the value-shift explanation of trade-off contrast.
\end{abstract}

When choosing between multiattribute alternatives, one is faced with the problem of having to make trade-offs between values on different attributes. For example, imagine a choice between two cars that differ primarily on the dimensions of gas mileage and safety features. Would you choose the car that gets high gas mileage but has few safety features or the one that gets low gas mileage but has many safety features? Ultimately the choice depends on whether the increase in gas mileage is worth the decrease in safety: a trade-off.

How are such trade-offs resolved? One approach to the problem is given by multiattribute utility theory, in which preference values are assigned to each level on a dimension and importance weights are assigned to the different dimensions (Von Winterfeldt \& Edwards, 1986). The overall utility of an alternative is determined by combining weights and values, typically using a weighted additive model:

$$
U_{i}=\sum_{j=1}^{m} w_{j} v_{i j}
$$

where $v_{i j}$ is the preference value of alternative $i$ on attribute $j$, $w_{j}$ is the weight assigned to that attribute, and $m$ indexes the set of relevant attributes. The choice rule is then to select the alternative with the highest overall attractiveness or utility, a difference operation. If one considers a dimensionwise processor of information in a pairwise choice situation, the weighted additive model can give rise to the weighted difference model. When Equation 1 is rearranged, the difference in utilities for two alternatives can be expressed as

This research was conducted under National Science Foundation Grant SBR-9319520. I would like to thank Mary Fleming for her help in carrying out these experiments.

Correspondence concerning this article should be addressed to Douglas H. Wedell, Department of Psychology, University of South Carolina, Columbia, South Carolina 29208. Electronic mail may be sent via Internet to wedell@sc.edu. the sum of the weighted differences in attribute values:

$$
U_{1}-U_{2}=\sum_{j=1}^{m} w_{j}\left(v_{1 j}-v_{2 j}\right)
$$

The representation of the choice process described by the weighted difference model of Equation 2 suggests two psychological processes involved in resolving trade-offs. The first is the determination of the relative weight given to each attribute dimension. The second is the valuation process whereby an attribute value is translated to a preference, utility, or attractiveness value. To return to the car example, a choice of the car with high gas mileage may reflect (a) relatively greater weight given to the dimension of gas mileage, (b) a greater difference in preference values on the gas mileage dimension than on the safety features dimension, or (c) some combination of the two. Note that the weighted additive and weighted difference models of Equations 1 and 2 are formally equivalent, but there may be important differences between the processes implied by each. First, the search process implied by the additive model is alternativewise but that implied by the difference model is dimensionwise. Second, Tversky (1969) has pointed out how differences may be subjected to a nonlinear transformation, such as a step function representing just noticeable differences. When any nonlinear function is applied to the differences in Equation 2, the two equations are no longer equivalent. For present purposes, however, the key observation is that the resolution of trade-offs in both models depends on how weights and values are determined.

The present set of experiments investigated how the recent context may be used to determine the weights and values used in resolving trade-offs. Context in this research is defined as the set of recently encountered alternatives within the relevant domain. Simonson and Tversky (1992) found that exposure to just a few pairs of contextual alternatives could significantly alter choices on a target pair. They referred to this phenomenon as trade-off contrast, and their later analysis modeled this effect in terms of the relative weighting of dimensions being determined by a contrast 
between current alternative values and previously encountered values from the contextual set (Tversky \& Simonson, 1993). Thus, the weight given to a specific difference on a dimension is greater when the range of previously encountered values on that dimension is small rather than large. This type of explanation falls into a class of context-effects models referred to as weight-change models (Wedell, 1991).

A second class of models that can explain context effects in choice locates these effects within the valuation process, and thus these have been referred to as value-shift models (Wedell, 1991). These models assert that rather than the $w_{j}$ s of Equations 1 and 2 changing with context, it is the subjective values assigned to the dimensional information, $v_{i j} s$, that change. The idea that value is dependent on context is consistent with a large literature describing the contextual dependence of value judgments (for partial reviews see Parducci, 1983; Wedell, 1994). The best evidence that trade-off contrast may be due to a shift in values rather than in weights is from a series of experiments reported by Mellers and Cooke (1994). However, their experiments used a single-stimulus judgment task with a large number of contextual trials, and so it is not clear that their results generalize to the effects that a relatively few contextual trials have on pairwise choice.

The design of the present set of experiments was conducted to more clearly distinguish the processes behind trade-off contrast in choice. There are several reasons to be concerned with whether context affects weights, values, or neither of these. First, one of the most common types of additive models is the weighted averaging model, in which weights sum to 1.0 (Anderson, 1981). For such models, increasing the weight on one dimension leads to decreases in the relative weights of the other dimensions. Thus, if context increases the weight of a targeted dimension, it will result in any additional dimensions receiving relatively less weight. This relationship is not predicted by a scale-change explanation, and, indeed, it formed the basis for Mellers and Cooke's (1994) conclusion that scale values rather than weights changed in the judgment task situation. Second, if context affects valuation, then these effects would extend to other tasks that might use different weighting schemes, such as similarity tasks. Third, it may be the case that weights and scale values are not affected but rather that the trade-off contrast effect is due to other psychological processes. In this research I raise two such possibilities: a responseequalization process and a dominance-valuing process. Both processes are plausible and have been demonstrated to produce similar types of context effects in other choice and judgment tasks (Wedell, 1991, 1995). Finally, determining which of multiple cognitive processes produce contextdependent choice may improve predictions in applied settings and increase our theoretical understanding of the processes underlying choice.

The primary method used in all three experiments was to develop and test path models corresponding to different process models of trade-off contrast. The use of path modeling allowed for distinguishing between different models on the basis of the patterns of correlations among independent and dependent variables predicted by the different process models. In addition, Experiment 2 attempted to differentiate between models using process-tracing measures, and Experiment 3 included manipulations of the

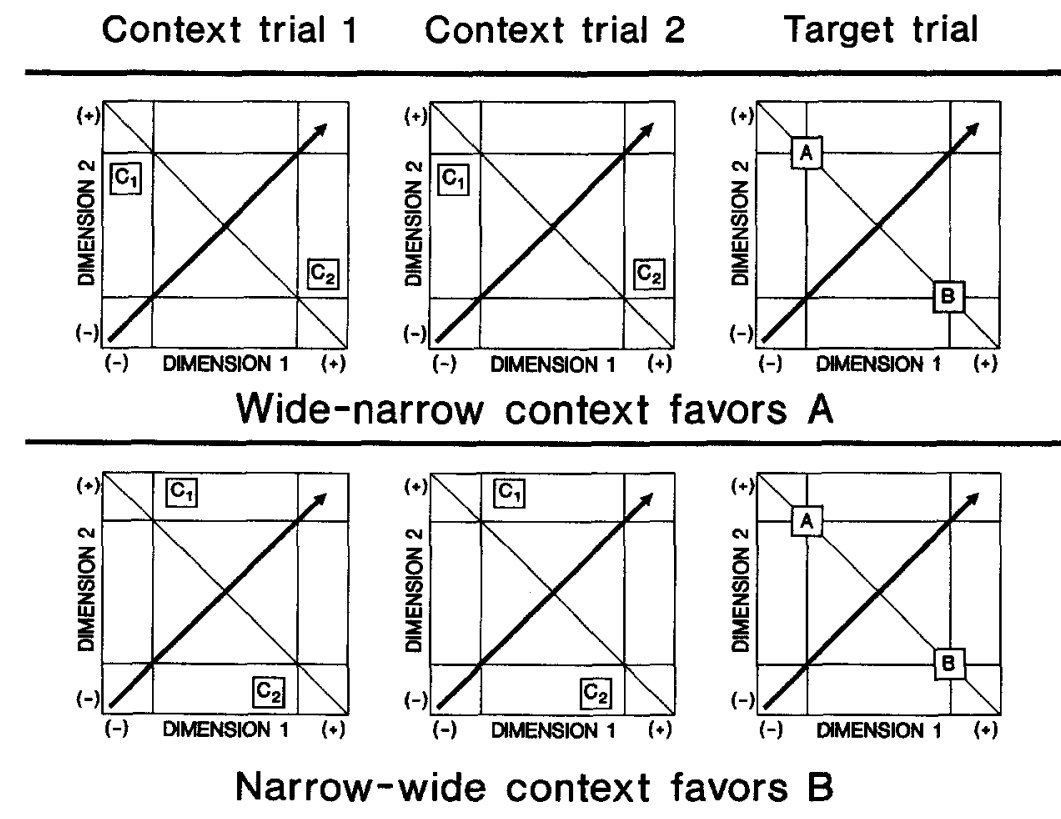

Figure 1. Basic experimental paradigm used to create trade-off contrast. Target alternatives are shown in the right graph at top and bottom. Contextual pairs favoring alternative $A$ (presented on the first two trials and shown in left and middle graphs) extend the range on Dimension 1 relative to the target pair. Contextual pairs favoring alternative $B$ (presented on the first two trials and shown in left and middle graphs of bottom) extend the range on Dimension 2 relative to the target pair. $C_{1}$ and $C_{2}$ refer to contextual stimuli. 
contextual set designed to distinguish between alternative accounts of trade-off contrast. Before examining the experimental manipulations and results, I first describe trade-off contrast in more detail and discuss how it might result from four different types of processes.

\section{Conditions Producing Trade-Off Contrast}

Figure 1 illustrates conditions that produce trade-off contrast in pairwise choice. The three successive graphs at the top of the figure correspond to three consecutive choice trials, with the first two trials representing contextual trials and the last representing the target trial. The rightmost graph describes the locations of the two target alternatives, $A$ and $B$, in a two-dimensional (2-D) space. Alternative $A$ has a relatively low value on Dimension 1 and a relatively high value on Dimension 2. Alternative $B$ has the opposite dimensional structure. For convenience, the representation in Figure 1 assumes that the preference vector is projected at a $45^{\circ}$ angle, reflecting equal weight given the two dimensions (i.e., $w_{1}=w_{2}$ ). In this graphic illustration, alternatives lying on the same $90^{\circ}$ projection from the preference vector are equally preferred and hence lie on the same equipreference contour. Because alternatives $A$ and $B$ lie on the same equipreference contour, they have equal overall utility according to the weighted additive model, and therefore $p(A, B)=p(B, A)=.50$.

The left and middle graphs at the top of the figure illustrate dimensional values of contextual stimuli $C_{1}$ and $C_{2}$
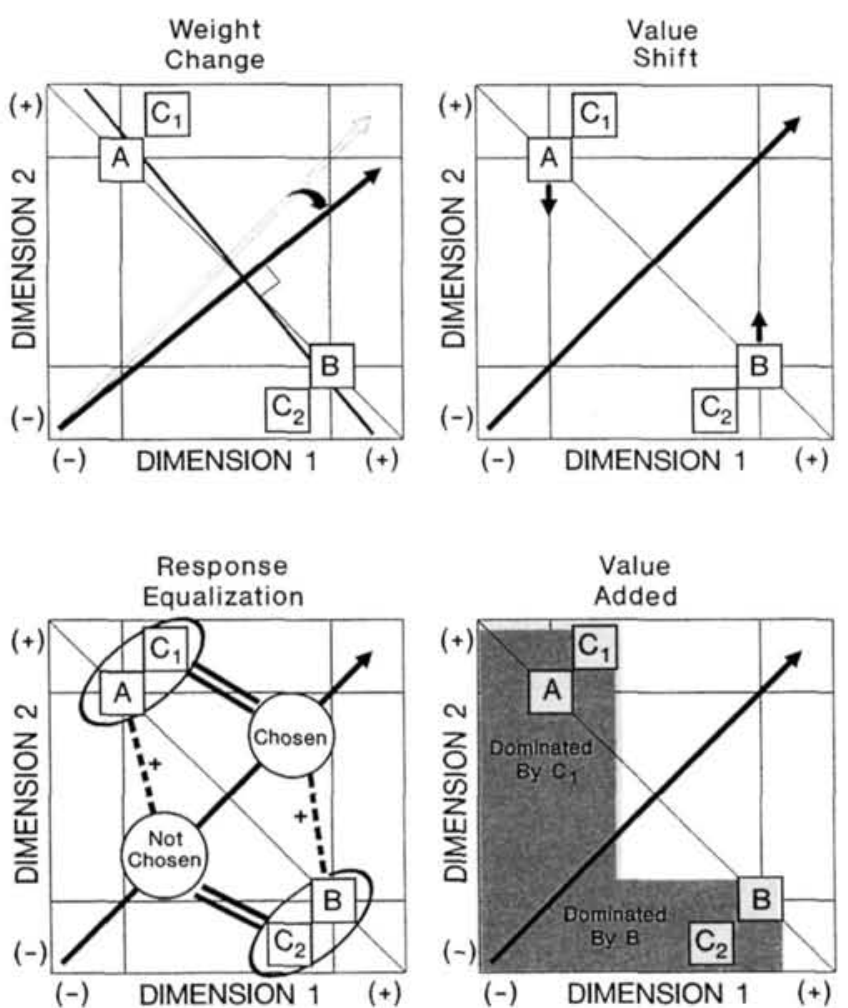

Figure 2. Four models of trade-off contrast. The values of contextual alternatives $C_{1}$ and $C_{2}$ are shown to illustrate the different processes, but on a given target trial only $A$ and $B$ are present. on Trials 1 and 2 of the wide-narrow condition that favors alternative $A$. Relative to the target pair, the choice alternatives in these graphs have a wide range of variation along Dimension 1 and a narrow range of variation along Dimension 2. Note that the basic contextual manipulation is to present pairs in which the range of variation is widened on the dimension corresponding to the lower value of the targeted alternative. Because $\mathrm{C}_{2}$ lies above the preference contour for $C_{1}$, it is likely to be chosen over $C_{1}$ on these contextual trials. The basic trade-off contrast effect consists of a greater proportion choosing $A$ over $B$ in the widenarrow context illustrated in graphs at the top of Figure 1 than in the narrow-wide context that would favor $B$ (illustrated in the bottom graphs of Figure 1). Various models of how prior exposure to contextual pairs alters choice proportions on the target set are discussed below.

\section{Weight-Change Model}

The weight-change model assumes that exposure to the contextual pairs alters the relative weighting or importance of the attribute dimensions. The model is graphically illustrated in the top left of Figure 2 for the situation in which the contextual set favors alternative $B$. The slope of the preference vector corresponds to the relative weight of Dimension 2 (i.e., $w_{2} / w_{1}$. When the range is extended on Dimension 2, the relative weight given to differences along Dimension 2 decreases, as illustrated by a decrease in the slope of the preference vector. Greater weighting of Dimension 1 favors alternative $B$ and is illustrated by $B$ lying on a higher preference contour than $A .^{1}$

Why should weight depend on context? There is strong evidence for the constructive nature of judgment and choice (Payne, Bettman, \& Johnson, 1992). One may argue that in many situations, importance weights are not well-defined

${ }^{1}$ To see how weight must change with range extension, consider the following stimulus coordinates in a 2-D space: $A=(4,6)$ and $B=(6,4)$. For convenience, let us assume that each dimension is weighted equally $\left(w_{1}=w_{2}=.5\right)$ and that utilities are identical to dimensional values. In the pairwise choice situation, the utility of $A$ will then be equal to $B$, that is, $.5(4.0)+.5(6.0)=.5(6.0)+$ $.5(4.0)=5.0$. Given equal utilities, then choice probabilities will be $p(A, B)=p(B, A)=.5$. Empirically, exposure to a prior-choice pair that extends the range on Dimension 1 but not on Dimension 2, such as $C_{1}=(2,6)$ and $C_{2}=(8,4)$, results in greater subsequent choice of $A$, that is, $p(A, B)>p(B, A)$. If we assume that only weights change and values remain constant, then the favoring of $A$ requires that $w_{1}(4.0)+w_{2}(6.0)>w_{1}(6.0)+w_{2}(4.0)$, which will only occur when $w_{1}<w_{2}$. Tversky and Simonson (1993) reached the same conclusion, but they linked change in weight to a comparison of the ratio of differences in dimensional values. They stated that in the 2-D situation, the weight of Dimension 1 will be greater than the weight of dimension 2 (i.e., $\beta_{1}>\beta_{2}$ in their notation) whenever the differences in attribute values of the contextual pair are greater on Dimension 2 than on Dimension 1, because these dimensional differences influence the perceived exchange rate. Thus, in the example described above, because the difference for background stimuli $C_{1}$ and $C_{2}$ described along Dimension 1 (i.e., $8-2=6$ ) is greater than along Dimension 2 $(6-4=2)$, the weight of Dimension 2 increases relative to Dimension 1 (i.e., $\beta_{1}<\beta_{2}$ ), and $A$ is favored. 
but must be constructed on line. Exposure to contextual stimuli then serves as one basis for determining weight. Simonson and Tversky (1992) reasoned that the contextual sets provide some cues concerning the current exchange rate between attribute dimensions. Thus, a wide range of values on one dimension accompanied by a narrow range of values on the other dimension would imply greater weight given to a unit difference on the narrow-range dimension.

Contrary to this prediction, several studies have provided evidence that weight increases with increase in range (Fischer, 1995; Goldstein, 1990; von Nitzsch \& Weber, 1993). In these studies the researchers have observed this relationship while using a variety of different methods (direct importance ratings, swing weights, regression weights, or weights inferred from value judgments). However, it should be noted that within the research cited above, the results have not always been consistent. For example, whereas some studies have found effects of range on direct importance ratings (Goldstein, 1990; von Nitzsch \& Weber, 1993), others have not (Fischer, 1995). Although these studies have raised doubts about the weight-change hypothesis, it still remains a viable explanation because none of the studies has examined how weights might relate to trade-off contrast effects.

\section{Value-Shift Model}

Within the weighted additive framework, an alternative interpretation of trade-off contrast is that exposure to contextual pairs alters how dimensional information is valued rather than how each dimension is weighted. The value-shift model is illustrated in the top right of Figure 2. The slope of the preference vector is unaffected by the contextual manipulation, but the subjective values assigned to the dimensional attributes of $A$ and $B$ are altered, with arrows indicating the direction in which the range extension on Dimension 2 would shift subjective values. Note that an alternative way to illustrate the value-shift model is to redraw the locations of all the alternatives along the affected dimension so that the differences in the dimensional values of $A$ and $B$ are reduced when the range for that dimension is widened.

The value-shift interpretation of trade-off contrast has been most fully tested by Mellers and Cooke (1994), who used attractiveness ratings rather than pairwise choice. In their work, they modeled the effects of manipulating attribute range on dimensional valuation by using Parducci's (1974) range-frequency theory of judgment. According to the range-frequency model, the subjective value along a dimension reflects a compromise between range and frequency principles. Mellers and Cooke (1994) focused primarily on the range principle, which states that the subjective value of a stimulus reflects the proportion of the range lying below it. If one assumes that the attractiveness value of a stimulus $i$ on a given dimension $j$ is a linear increasing function of its physical value on that dimension, $X_{i j}$, then the range value of the stimulus can be expressed as

$$
v_{i j}=\left(X_{i j}-X_{\min , j}\right) / \text { range }_{j},
$$

where range ${ }_{j}$ is defined by the difference between maximum and minimum subjective values along that dimension, and $X_{\min , j}$ is the minimum subjective value on dimension $j$.
Substituting the valuation expression given by Equation 3 into Equation 2 and then simplifying results in the following expression:

$U_{1}-U_{2}=\sum_{j=1}^{m} w_{j}\left(v_{1 j}-v_{2 j}\right)=\sum_{j=1}^{m} w_{j}\left(X_{1 j}-X_{2 j}\right) /$ range $_{j}$.

Equation 4 describes how increasing the range on one dimension will lead to a decrease in the difference of attractiveness values along that dimension. Mellers and Cooke (1994) showed that although both weight-change and value-shift models predicted the same preference ordering of alternatives, they differed in predictions of effects on marginal means in a factorial design. If judgments followed an averaging process, then increased weight on one dimension should result in decreased weights for the other dimensions and thus a reduction of the variability of the marginal means. The value-shift model predicted no effect on the marginal means corresponding to the other dimensions. Results supported the value-shift model over the weightchange model. Although Mellers and Cooke (1996) found similar contextual effects on choice, they acknowledged that their design did not distinguish whether these effects on choice were due to changes in weighting or in valuation. ${ }^{2}$

\section{Response-Equalization Model}

Although context could operate on weighting or valuation, it might also operate on response-selection mechanisms. Evidence for response equalization has long been noted in the literature on choice and judgment (Luce \& Galanter, 1963). For example, Parducci's (1965) original formulation of range-frequency theory described the frequency principle in terms of a response-equalization tendency. In testing models of contrast effects in paired comparisons, Wedell (1995) has provided evidence for a response-equalization process in addition to stimulus-based contrast processes. In those experiments, research participants judged which of two squares was larger. On each trial, one square was printed in red and the other in blue. The distribution of sizes differed for red and blue squares so that one set of squares comprised mostly larger sizes. In comparisons of similar-sized squares, the probability of being judged larger increased when the square was selected from the distribution of smaller squares. Evidence from three experiments supported a two-process model of these contrast effects, one based on stimulus comparisons and the other based on a response-equalization tendency.

Although the comparative judgment task described above differs from the typical choice task used in examining

\footnotetext{
${ }^{2}$ It should be noted that in addition to the range-valuing model of Equation 4, the frequency principle of range-frequency theory (Parducci, 1983) can also account for the effect. The frequency principle states that the value of a stimulus depends on its rank. In the example shown in Figure 1, the rank difference between $A$ and $B$ on Dimension 1, which favors $B$, is 5 ; the rank difference between $A$ and $B$ on Dimension 2, which favors $A$, is only 1 . Hence, insofar as valuation depends on ranks, the differences in ranks for the narrow-wide context would favor $B$.
} 
trade-off contrast in several ways, the response-equalization hypothesis represents a viable confound hypothesis explaining trade-off contrast. Furthermore, it predicts correlational patterns that can be tested using path analysis. For response equalization to produce the trade-off contrast effects, alternatives must be implicitly categorized into two groups, one that is high on Dimension 1 and low on Dimension 2, and the other that has the opposite dimensional structure. This type of categorization would be predicted from any of a number of similarity based models of categorization (e.g., Nosofsky, 1992). Alternatives $A$ and $C_{1}$ are close in the 2-D space as are alternatives $B$ and $C_{2}$, but these two clusters of alternatives are quite far apart. Thus, if decision makers were implicitly categorizing alternatives based on similarity, these two categories would emerge.

The nature of the contextual manipulation is such that when the context favors $B$, the contextual alternative which is closest to $A$ (i.e., $C_{1}$ ) is most likely to be chosen on the contextual trials. This is illustrated in the bottom left of Figure 2. Alternative $C_{1}$ falls on a preference contour that is well above the contour for alternative $C_{2}$, so it is likely to be selected. The selection of $C_{1}$ is represented by a link to the response "chosen," and $C_{2}$ is linked with the response "not chosen." Because $A$ is grouped with $C_{1}$ and $B$ is grouped with $C_{2}$, the response-equalization principle implies that when the utilities of $A$ and $B$ are similar, the alternative linked with the response "not chosen" is more likely to be chosen. If response equalization contributes to the trade-off contrast effect, then the generality of the effect will depend on how decision makers respond to prior contextual stimuli.

\section{Value-Added Model}

A final model that should be considered is based on the idea that there may be important values that are not captured by weights or dimensional values. For example, one of these values is the justifiability of the choice. Support for the role of justifiability of choices was demonstrated by Simonson (1989), who found larger context effects in trinary choice when participants anticipated having to justify their choices. More generally, several researchers have argued that people look for reasons to support their choices (Shafir, 1993; Shafir, Simonson, \& Tversky, 1993; Simonson, 1989). These reasons may go beyond the importance of dimensions or values of stimuli along the dimension.

Wedell (1991) found evidence to support the hypothesis that context effects in trinary choice were not produced solely by changes in values or weights associated with the extension of the range along one dimension but rather by the value added to an alternative because it asymmetrically dominated a decoy alternative. ${ }^{3}$ Asymmetric dominance refers to the situation in which an alternative is dominated by one alternative but not another. The fact that one alternative dominates another may add to the value of the dominating alternative because it provides additional reasons for choosing that alternative. Wedell (1991) found that adding a decoy alternative that extended the range on one dimension but was symmetrically dominated by both alternatives did not produce a contextual effect. Because extension of the range with asymmetrically dominated alternatives did produce the effect, Wedell (1991) reasoned that asymmetric dominance rather than range extension was key to producing the context effect. More recently, Wedell and Pettibone (1996) have provided judgment data that directly implicates both valueshift and value-added processes as contributing to the effects of an asymmetrically dominated decoy.

The bottom right of Figure 2 illustrates how the valueadded model might operate in the present task situation. In this case, dominance of an alternative is assumed to add to that alternative's value, and being dominated by an alternative is assumed to detract from that alternative's value. The shaded regions represent alternatives that are dominated by $B$ or by $C_{1}$. As can be seen, $B$ dominates one contextual alternative, $C_{2}$, and $A$ is dominated by one contextual alternative, $C_{1}$. The attractiveness of $A$ should then decrease, because there is an alternative from a previous choice pair that clearly dominates it. The attractiveness of $B$ should be enhanced, because there is an alternative from a previous choice pair that it clearly dominates.

The trade-off contrast effect is very similar to the decoy effects observed in trinary choice with asymmetrically dominated decoys. Indeed, Simonson and Tversky (1992) linked these two effects, suggesting a common mechanism underlying the effects of local and global contextual manipulations. Because dominance valuing has been demonstrated to be a viable explanation of local context effects in the decoy situation (Wedell, 1991; Wedell \& Pettibone, 1996), it is important to test whether this type of process might extend to the global context effects demonstrated in trade-off contrast.

\section{Experiment 1: A Path Analysis of Trade-Off Contrast}

The four models described above provide plausible interpretations of the trade-off contrast effect in choice. One way to distinguish among them is to examine whether the models make differential predictions for correlations between potential mediating variables. Structural equation or path modeling provides a powerful tool for determining whether patterns of observed correlations fit or do not fit theoretical predictions (for an overview see McArdle, 1996). In path modeling, theoretical relationships are represented as causal paths among relevant variables, and these paths are used to generate a predicted correlation matrix for the relevant variables. Model testing consists of determining which model or models best fit the observed correlation pattern. Typically, path modeling consists of two phases: an initial exploratory phase in which the path model is developed and refined, followed by a confirmatory stage in which the model is cross-validated on new data. The path models developed and tested in Experiments 1-3 are based on the four theoretical models described above.

First consider the weight-change model. To test this model, one must obtain a measure of the relative weight of the dimensions begin compared. In the present studies, this was achieved by having participants make judgments of the relative importance of the two dimensions. The top of Figure 3 illustrates the causal relationships between the manipula-

\footnotetext{
${ }^{3}$ Dominance refers to the situation in which an alternative has a superior value to another alternative on one attribute and has superior or equal values to that alternative on all other attributes.
} 


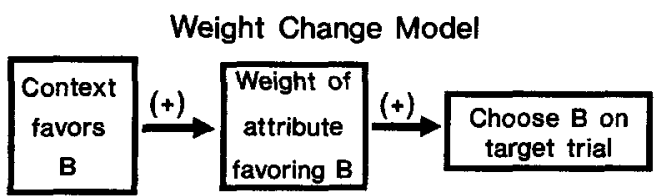

Response Equalization Model
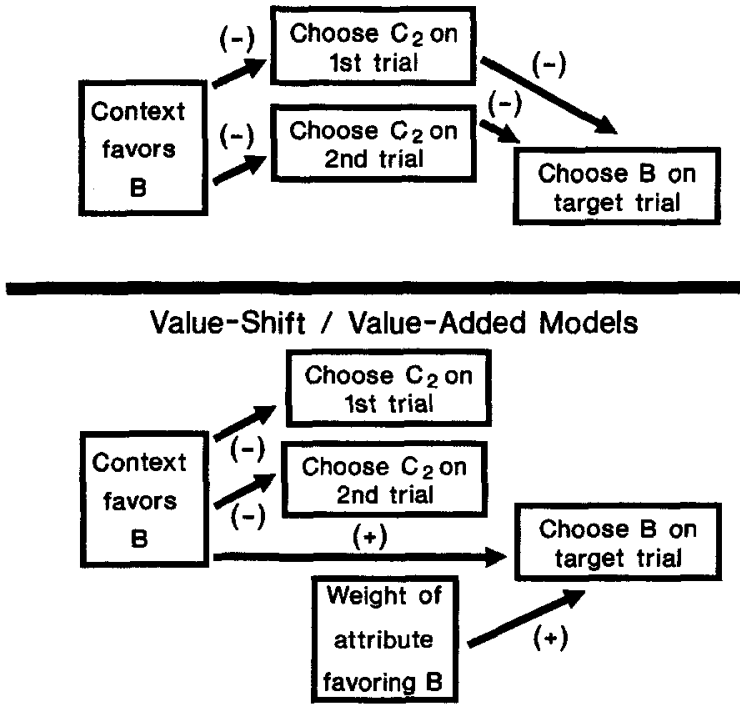

Figure 3. Basic path models corresponding to weight-change, response-equalization, value-shift, and value-added models. $\mathrm{B}=$ alternative $B ; C_{2}=$ contextual stimulus.

tion of context and measures of weight and choice on the target trial as described by the weight-change model. The model assumes a mediating relationship: When the context favors $B$, the weight assigned the attribute favoring $B$ should increase and lead to a higher probability of choosing $B$ on the target trial. The strongest evidence supporting the weight-change model would be if both of the positive path coefficients shown were significant and the direct path between context and target choice was nonsignificant. A failure to find a positive relationship between weight and choice on the target trial would suggest that the measure of weight was not valid and would thus call into question the results of the path analysis.

The middle portion of Figure 3 illustrates predicted paths generated from the response-equalization model. When the context favors $B$, one is less likely to choose $C_{2}$ (which is similar to $B$ ) on Contextual Trials 1 and 2 , because $C_{2}$ is designed to be inferior to $C_{1}$ (see Figure 1). Thus, there should be negative path coefficients between context and choice on the first two trials. Response equalization assumes that the tendency to choose $C_{2}$ on contextual trials would lead to the tendency not to choose $B$ on the target trial, which is represented by paths with negative coefficients between context trial choices and target trial choices. The mediating effect of response equalization is thus represented by the product of the paths between the contextual manipulation, choices on contextual trials, and choice on the target trial.
The strongest evidence supporting the response-equalization model would be if the four paths shown in the middle of Figure 3 were significant and negative, with the direct path between context and target choice being nonsignificant.

The value-shift and value-added models do not have manifest variables that are easily measured and used in the path analysis. Thus, these models are supported to the extent that a direct path between the contextual condition and target choice is observed and the mediating paths by means of weight or responses on contextual trials are not significant. This situation is illustrated at the bottom of Figure 3. The pattern shown in Figure 3 assumes that context affects choices on contextual trials, but these choices do not affect choice on the target trial. It also assumes that weight affects choice on the target trial but that weight is not related to context.

The path modeling of Experiment 1 is primarily exploratory in nature. The path models tested were constructed on the basis of the paths described in Figure 3, but with paths added or subtracted to better fit the data. The path model developed in Experiment 1 was then cross-validated in Experiments 2 and 3 to determine whether the model correctly predicted correlation patterns in these replications.

\section{Method}

Participants and design. Participants were 159 students from the University of South Carolina who received class credit for participating. The major independent variable, context, was manipulated between subjects at two levels (context favors $A$ or $B$ ). Choice domain was manipulated within subjects and was used to create 10 replicates of the contextual manipulation. Dependent variables were (a) choices on each of two contextual trials, (b) choice on the target trial, and (c) rating of the relative importance of the attributes within each choice domain.

Stimulus sets. Participants were exposed to 16 stimulus sets, 6 of which were filler sets. ${ }^{4}$ Each set consisted of three choice pairs. The first two choice pairs were contextual pairs and the third was the target pair. Each choice pair described values of two alternatives along two attribute dimensions. Contextual and target pairs followed the design illustrated in Figure 1. Target $A$ had a less attractive value than target $B$ on Dimension 1 and a more attractive value than $\operatorname{target} B$ on Dimension 2 . When the context favored $A$, the contextual pairs consisted of one alternative with a less attractive value than $A$ on Dimension 1 and an intermediate value on Dimension 2 and a second alternative with a more attractive value than alternative $B$ on Dimension 1 and an intermediate value on Dimension 2 (see top of Figure 1). This manipulation extended the range of variation on Dimension 1 relative to the target pair. When the context favored $B$, the values of contextual alternatives were manipulated in the opposite fashion (see bottom of Figure 1). The 10 choice domains included choices between apartments, computers, cars, restaurants, airline tickets, boats, mechanics, compact disc (CD) players, jobs, and microwaves. For example, in choosing between restaurants, altemative $A$ consisted of a $\$ 50$ dinner for two with a 10 -min wait, and alternative $B$ consisted of a $\$ 30$ dinner for two with a 45-min wait. When the context favored $A$,

${ }^{4}$ Of the 6 filler items, 4 had a similar contextual structure to the experimental trials but were manipulated in the opposite direction. Results from these 4 trials were similar to those for the 10 experimental trials. 
contextual choice pairs included the possibility of a $\$ 65$ dinner and a $\$ 25$ dinner, extending the range on Dimension 1 . When the context favored $B$, contextual choice pairs included the possibility of a 5-min and a 55-min wait, extending the range on Dimension 2. The alternatives were displayed in a matrix in which the two columns corresponded to the two choice alternatives, and the two rows corresponded to the relevant attributes. (The stimulus materials used in Experiments 1-3 are presented in Tables A1 and A2 in the Appendix.)

Procedure. Presentation of information and recording of responses were carried out by means of microcomputers. Instructions explained that the participant would be choosing between pairs of alternatives in several domains. An example of a typical display was presented, along with instructions on how to read the information within the display. The 16 choice sets corresponding to the 16 domains were presented in random order. For each set, the domain and attributes were presented first on a separate screen. The participant then pressed a key to begin the set of three trials for that domain. The first two trials presented contextual pairs, and the target pair was presented on the third trial. The computer randomized which alternative appeared on the left or right column. Participants indicated their choice by pressing 1 or 2 , which corresponded to the labels of the alternatives.

After making 48 choices, the participants were asked to make importance ratings for each of the 16 choice domains. The display of the domain and attributes was presented with no alternative information. Participants indicated which of the two attributes was most important to them and then how much more important that attribute was on a 9-point scale $(1=$ not very much more important, $9=$ very much more important). This rating procedure required that participants directly weigh the relative importance of the two dimensions rather than consider them separately.

\section{Results}

Tests for context effects on choice. For the 10 relevant sets, the number of times the participant chose alternative $B$ on the target and contextual trials was calculated, along with the mean importance rating assigned to the dimension favoring alternative $B$. The means for these dependent measures and the results of $t$ tests carried out on them are shown in Table 1 . Context significantly altered choice on the target trial. Alternative $B$ was chosen $43 \%$ of the time when the context favored $A$ and $51 \%$ when the context favored $B$. Context also significantly altered choice on the contextual trials, but in the opposite direction. Alternative $C_{2}$ was chosen approximately $80 \%$ of the time when the context favored $A$ and only $23 \%$ of the time when the context favored $B$. Finally, context significantly affected mean

Table 1

Choice and Rating Data (Experiment 1)

\begin{tabular}{lllcc}
\hline \multirow{2}{*}{$\begin{array}{c}\text { Favored } \\
\text { alternative }\end{array}$} & \multicolumn{2}{c}{ Proportion choosing $C_{2}$ or $B$} & \multirow{2}{*}{\begin{tabular}{c} 
Relative \\
weight \\
\cline { 2 - 4 } Dimension 1
\end{tabular}} \\
\cline { 2 - 4 }$A$ & Trial 1 & Trial 2 & Trial 3 & Dimen \\
$B$ & .806 & .791 & .425 & 1.982 \\
Difference & $.575^{* * *}$ & $.570^{* * *}$ & $-.081 * *$ & $4.091 * * *$
\end{tabular}

Note. $\quad N=159$.

${ }^{* *} p<.01 . \quad * * * p<.001$
Table 2

Correlation Matrix From Experiment 1

\begin{tabular}{lccccc}
\hline \multicolumn{1}{c}{ Variable } & 1 & 2 & 3 & 4 & 5 \\
\hline 1. Context $B$ & - & & & & \\
2. Weight $B$ & $-.629^{* * *}$ & - & & & \\
3. Choice 1 & $-.883^{* * *}$ & $.759^{* * *}$ & - & & \\
4. Choice 2 & $-.889^{* * *}$ & $.753^{* * *}$ & $.924^{* * *}$ & - & \\
5. Target $B$ & $.217^{*}$ & $.211^{*}$ & -.121 & -.097 & - \\
\hline
\end{tabular}

Note. $\quad N=159$. Context $B=$ context favors $B$; Weight $B=$ relative weight of attribute favoring $B$; Choice $1=$ choice of $C_{2}$ on Contextual Trial 1; Choice $2=$ choice of $C_{2}$ on Contextual Trial 2; Target $B=$ choice of $B$ on target trial.

${ }^{*} p<.05 . \quad{ }^{* *} p<.01 . \quad{ }^{* * *} p<.001$

importance weight, but in the direction opposite from that proposed by the weight-change hypothesis. The dimension favoring $B$ (Dimension 1) received a significantly greater importance rating when the context favored $A$ than when the context favored $B$.

Another way to look at the pattern of results is to examine the correlations between the independent variable-contextand the four dependent variables. This correlation matrix is presented in Table 2. The first column reflects the results just reported, with context significantly correlated with the importance weight and choices on contextual and target trials. The remaining correlations represented the interrelations among the dependent variables. Only two of these correlations were not significant: those corresponding to the correlation between choice on the target trial and choice on each of the contextual trials.

Path modeling. A set of path analyses was conducted on the correlation matrix of Table 2 to test the different models shown in Figure 3; the analyses were conducted using the maximum likelihood estimation procedures from EZPATH (Steiger, 1989). Figure 4 presents the path model with the best fit. All path coefficients shown in the model were significant, and no additional path coefficients could be added to significantly decrease the maximum likelihood chi-square statistic. The model included the positive path from the weighting variable to choice on the target trial,

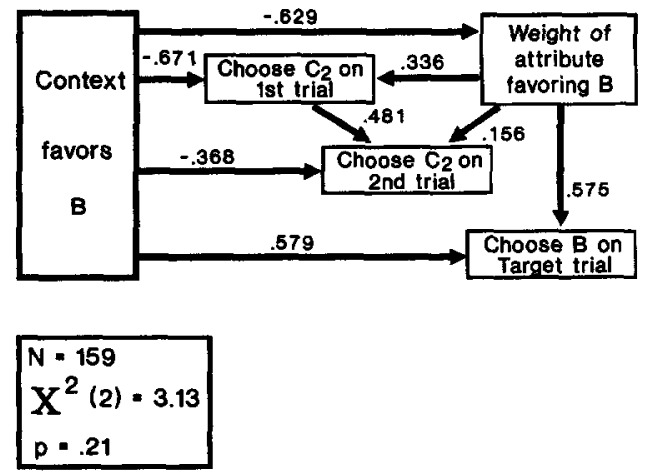

Figure 4. Results of a path analysis on the correlation matrix shown in Table 2 (Experiment 1 ). $\mathrm{B}=$ alternative $B ; \mathrm{C}_{2}=$ contextual stimulus. 
which supports the validity of the weighting measure. The negative paths from context to choice on contextual trials were anticipated from the nature of the manipulation. There are three paths not shown in Figure 3. Two of these represented positive paths from weight to choice on contextual trials, which simply indicate that greater weight of Dimension 1 favors alternative $C_{2}$. The third was a positive path from choice on the first trial to choice on the second trial. Given the structural similarity between alternatives on these trials, the addition of this path seemed reasonable.

The path model shown in Figure 4 is not consistent with either weight-change or response-equalization models, but it is consistent with value-shift and value-added models. First consider the weight-change model. The positive paths between weight and choices on the target and context trials indicates that the higher the rated importance of the attribute favoring $B$, the more likely participants were to choose $B$. This relationship helps to establish the validity of the weighting measure. Although weight positively correlated with choice on the target trial, it negatively correlated with context. Thus, the path modeling indicates that the mediating effect of weight on choice is in the opposite direction predicted by the weight-change model.

The model also provides no support for the responseequalization hypothesis. Although the contextual manipulation strongly influences choice on the contextual trials in a manner consistent with the response-equalization model, there is no direct path from choices on contextual trials to choice on the target trial. Thus, the path model indicates that the effects of the contextual manipulation on the target-trial choice is not contingent on responses made to contextual stimuli. Finally, the occurrence of a direct path between context and choice on the target trial is consistent with both the value-shift and value-added models.

\section{Discussion}

The results of Experiment 1 provide evidence against both weight-change and response-equalization models of tradeoff contrast. The positive correlations between importance ratings and choices support the validity of those ratings as a measure of attribute weight. However, the contextual manipulation led to a reduction in the rated importance for the dimension favoring the targeted alternative rather than the increase predicted by the weight-change model. Thus, the net effect of the contextual shift in importance was to work against the observed trade-off contrast effect. The increase in weight for the range-extended dimension replicates previous research (Fischer, 1995; Goldstein, 1990; von Nitzsch \& Weber, 1993). One might argue that the observed relationship between rated importance and the contextual manipulation was due to participants' recalling their choices and giving greater importance to the dimension favored by the majority of choices. However, this same relationship between weight and range has been found when no choices have been made by participants (Fischer, 1995; Wedell \& Pettibone, 1996). Experiment 1 differed from the previous studies in that those studies were not designed to evaluate how weight varied in the trade-off contrast paradigm. The results of Experiment 1 replicate the positive relationship between weight and range extension found previously, providing evidence contrary to the weight-change explanation of trade-off contrast.

That the relationship between context and target-trial choice required no mediating path through responses to contextual trials argued against the response-equalization hypothesis. Instead, the negative correlations between responses on contextual trials and responses on the target trial, although not significant, were modeled as spurious correlations.

The path model of Figure 4 supports both the value-shift and value-added models in that trade-off contrast effects were not mediated by either importance weights or responses to prior contextual trials. According to these models the direct path between the experimental variable and choice on the target trial indicates either that subjective values were affected by the range manipulation or that perceived dominance relations added value to the targeted alternative.

\section{Experiment 2: Process-Tracing Measures}

In Experiment 1 the correlational structure between dependent measures was used to test between models of trade-off contrast. Experiment 2 tested the replicability of the pattern obtained in Experiment 1. In addition, Experiment 2 included process-tracing measures in an attempt to distinguish among models. Thus, participants performed the same task as in Experiment $\mathbf{1}$ but used a mouse device to uncover information for viewing so that looking time and frequency of looks at the four relevant pieces of information could be recorded.

The test of the models required that looking time and number of looks be operationally linked to theoretical constructs such as weight. Wedell and Senter (1997) have demonstrated a clear link between looking measures and weight in both single-stimulus judgment and pairwise choice tasks. Participants in that study were asked either to judge the success of students in a given major or to choose which of two students would be more successful in that major. Students were described by verbal and math aptitude scores, and the major either emphasized verbal scores (e.g., an English major) or math scores (e.g., an engineering major). In both choice and judgment, the change in the focus of the task resulted in a strong change in weights inferred from responses, with verbal scores receiving much greater relative weight than math scores in the English-major prediction task than in the engineering prediction task. Furthermore, the dimension receiving the greater weight also received the greater looking time and frequency of looks in both judgment and choice. Finally, individual differences in weight were well predicted by individual differences in looking time.

Assuming a positive correspondence between weight and looking measures, the weight-change model predicts greater looking time and frequency of access for information along the narrow dimension during the target trial. Note that if the importance ratings reflect weight, then the dimension receiving the higher importance rating should attract greater 
looking time. A positive correlation between the reports of relative importance and the relative looking time for the dimensional information would provide additional validation for both measures. Such a correspondence would also provide additional evidence against the weight-change model, because the importance ratings provided evidence that the wider dimension received greater weight, contrary to the weight-change model.

It is more difficult to generate a prediction for looking time from the value-shift model. Weight has been associated with greater cognitive processing and therefore with greater looking time, but the valuation process has not been explicitly tied to looking time. One way to do so, however, is to consider the difficulty of the valuation process. Range manipulations have been found to lead to greater errors in identification of the same stimuli in an absolute identification task (Gravetter \& Lockhead, 1973; Lockhead \& Hinson, 1986). Explanations of these effects typically assume that one component of error is based on the location of category thresholds, which are dependent on the stimulus range. Similar effects have also been reported for category ratings (Parducci \& Perrett, 1971). There is ample evidence that more difficult discriminations result in longer latencies (e.g., Petrusic, 1992). Therefore, a value-shift model based on valuing stimuli relative to the attribute range would predict greater looking time for the wider dimension. Note that this is just the opposite prediction than that generated for the weight-change model.

Process-tracing predictions are even more difficult to generate for the remaining two models. The responseequalization model operates at response selection and hence is difficult to tie to stimulus information. The value-added model assumes comparisons to alternatives from previous trials that are held in memory. This type of comparison is difficult to pin down to information presented on the screen.

\section{Method}

Participants and design. Participants were 98 students from the University of South Carolina who received class credit for participating. Each participant made three binary choices in each of 16 domains ( 8 domains constituting Set 1 , and 8 domains constituting Set 2). For each set, the major independent variable, context, was manipulated between subjects at two levels (context favors $A$ or $B$ ). However, across sets, context was manipulated within subjects. Thus, for half of the participants, alternative $A$ was favored in Set 1, and alternative $B$ in Set 2; and for the other half, the reverse was true. This design provided essentially two replicates (Sets 1 and 2) of the between-subjects contextual manipulation of Experiment 1. Dependent variables were (a) choices on each of two contextual trials, (b) choice on the target trial, (c) rating of the relative importance of the attributes within each choice domain, (d) looking time for each attribute by alternative region, and (e) number of looks at each region.

Stimulus sets. Set 1 consisted of 8 of the 10 experimental sets in which context was manipulated in Experiment 1. Set 2 consisted of 2 of the previously manipulated sets and 6 new sets. The choice domains for Set 1 were renting an apartment, buying a computer, buying a car, going to a restaurant, buying a plane ticket, choosing a boat, hiring a mechanic, and buying a CD player. The choice domains for Set 2 were choosing between job offers, buying a house, buying an electric keyboard, buying a mini-LCD TV, choosing a preschool, buying a microwave, buying a parking space, and buying a video camera.

Procedure. The procedure was very similar to that of Experiment 1 except that a process-tracing procedure was implemented. Attribute values were hidden in four boxes on the screen. The decision maker would open a box by moving the mouse cursor into that region. When the mouse cursor left the region, the box would close. Boxes could be opened and closed as many times as the participant wished. To record a response, the participant moved the mouse cursor above the desired option and clicked either mouse button. A practice session acquainted the participant with the use of the mouse.

\section{Results}

Tests for context effects on choice. Table 3 presents the choice proportions and mean dimensional importance ratings for Sets 1 and 2. The results replicated those of Experiment 1 except that the contextual manipulation did not significantly affect choice on the target trial for Set 1 . Once again, significantly greater subjective weight was attributed to the dimension on which the favored alternative was poorest, which is inconsistent with the weight-change hypothesis.

Process-tracing measures. The looking-time data are presented separately for Sets 1 and 2 in Table 4 . The looking times for each set were analyzed within a three-way repeated measures analysis of variance (ANOVA), with dimension and alternative constituting within-subjects variables and context constituting the between-subjects variable. Both ANOVAs revealed a significant main effect of dimension, $F \mathrm{~s}(1,96)=12.0$ and 8.8 , respectively, $p \mathrm{~s}<.01$. In both cases, this effect reflected greater looking time on Dimension 1. Because Dimension 1 was always topmost on the screen, this main effect may have simply reflected a tendency to look longer at the information examined first. Under the assumption of greater looking time corresponding to greater weight, the weight-change hypothesis predicted relatively greater looking time for Dimension 1 when the context favors $B$. This interaction was significant for Set 2 ,

Table 3

Choice and Rating Data for Sets 1 and 2 (Experiment 2)

\begin{tabular}{|c|c|c|c|c|}
\hline \multirow{2}{*}{$\begin{array}{l}\text { Favored } \\
\text { alternative }\end{array}$} & \multicolumn{3}{|c|}{ Proportion choosing $C_{2}$ or $B$} & \multirow{2}{*}{$\begin{array}{c}\text { Relative } \\
\text { weight } \\
\text { Dimension } 1\end{array}$} \\
\hline & Trial 1 & Trial 2 & Trial 3 & \\
\hline \multicolumn{5}{|c|}{ Set 1} \\
\hline $\begin{array}{l}A \\
B\end{array}$ & $\begin{array}{l}.797 \\
.155\end{array}$ & $\begin{array}{l}.802 \\
.120\end{array}$ & $\begin{array}{l}.370 \\
.380\end{array}$ & $\begin{array}{r}2.341 \\
-1.750\end{array}$ \\
\hline Difference & $.642 * * *$ & $.682 * * *$ & -.010 & $4.091 * * *$ \\
\hline \multicolumn{5}{|c|}{ Set 2} \\
\hline $\begin{array}{l}A \\
B\end{array}$ & $\begin{array}{l}.670 \\
.107\end{array}$ & $\begin{array}{l}.745 \\
.083\end{array}$ & $\begin{array}{l}.240 \\
.388\end{array}$ & $\begin{array}{r}0.418 \\
-1.872\end{array}$ \\
\hline Difference & $.563^{* * *}$ & $.662 * * *$ & $-.148 * * *$ & $2.290 * * *$ \\
\hline
\end{tabular}

Note. $\quad N=98$.

$* * * p<.001$ 
Table 4

Mean Looking Times (in Milliseconds) for Sets 1 and 2 (Experiment 2)

\begin{tabular}{|c|c|c|c|c|c|c|}
\hline \multirow[b]{3}{*}{ Dimension } & \multicolumn{3}{|c|}{ Context favors $A$} & \multicolumn{3}{|c|}{ Context favors $B$} \\
\hline & \multicolumn{2}{|c|}{ Alternative } & \multirow[b]{2}{*}{ Sum } & \multicolumn{2}{|c|}{ Alternative } & \multirow[b]{2}{*}{ Sum } \\
\hline & $A$ & $B$ & & $A$ & $B$ & \\
\hline \multicolumn{7}{|c|}{ Set 1} \\
\hline \multicolumn{7}{|l|}{1} \\
\hline$M$ & 1,193 & 1,189 & 2,382 & 1,347 & 1,366 & 2,713 \\
\hline $2^{S E}$ & 78 & 95 & & 77 & 93 & \\
\hline$M$ & 1.022 & 978 & 2000 & 1.307 & 1287 & 2504 \\
\hline$S E$ & 83 & 78 & & 82 & 76 & \\
\hline Sum & 2,215 & 2,167 & 4,382 & 2,644 & 2,643 & 4,685 \\
\hline \multicolumn{7}{|c|}{ Set 2} \\
\hline \multicolumn{7}{|l|}{1} \\
\hline$M$ & 1,270 & 1,175 & 2,445 & 1,307 & 1,249 & 2,556 \\
\hline \multicolumn{2}{|l|}{$2^{S E}$} & 86 & & 91 & 87 & \\
\hline & & & 247 & & & 2720 \\
\hline$S E$ & 88 & 85 & $2,4+1$ & $\begin{array}{r}1,004 \\
90\end{array}$ & $\begin{array}{r}1,04 J \\
86\end{array}$ & 2,129 \\
\hline Sum & 2,560 & 2,332 & 4,892 & 2,391 & 2,294 & 4,685 \\
\hline
\end{tabular}

$F(1,96)=9.0, p<.01$, which was the set for which a significant context effect was obtained. Looking times were nearly identical for Dimensions 1 and 2 when the decoy favored $A$, but they were more than $400 \mathrm{~ms}$ greater for Dimension 1 when the decoy favored B. This interaction pattern was in the opposite direction, although not significant $(.10>p>.05)$, for Set 1 .

Table 5 presents the frequency of looks at information separately for Sets 1 and 2. Three-way repeated measures ANOVAs were used to analyze the data for each set. The Dimension $\times$ Context interaction was significant for both sets, but in opposite directions. For Set 1, Dimension 1 was examined relatively more often when context favored $A$, $F(1,96)=9.1, p<.01$, but for Set 2 , Dimension 1 was examined relatively more often when context favored $B$, $F(1,96)=12.2, p<.001$. These mixed results are difficult to interpret. One might argue that the results for Set 2 are most relevant, because this set had a significant contextual effect for choice on the target trial. On the other hand, it should be remembered that the participants in Set-1-contextfavors- $A$ are the same as those in Set-2-context-favors- $B$. The pattern of looking times and fixations are similar for these participants in the two conditions, suggestive of a possible carry-over effect.

Path modeling. The correlation matrices for Sets 1 and 2 are presented in Table 6 . These correlations provide an opportunity to determine whether the pattern found in Experiment 1 is sustained. Separate path analyses were conducted for Sets 1 and 2 by using the same five variables analyzed in Experiment 1. The path model determined for Experiment 1 and shown in Figure 4 was fit to each set in a confirmatory analysis. In each case, the path model of
Experiment 1 provided an adequate fit to the data set $(p>$ .05 ). The path coefficients had the same valence as in Experiment 1. All path coefficients were significant for Set 1. The only nonsignificant path for Set 2 was the direct connection between rated weight and choice on the second trial. Thus, the conceptual relationships described in the path model of Experiment 1 replicated twice in Experiment 2. Because the correlations between the process measures and relevant experimental variables differed across the two sets, the path models that included the processing pattern information were inconsistent across the two sets.

\section{Discussion}

One aim of Experiment 2 was to provide replications of the pattern of results from Experiment 1. Experiment 2 generally replicated Experiment 1 for the five variables common to the two experiments. The path model developed from Experiment 1 adequately fit both sets of data from Experiment 2. Once again, the measure of rated importance was found to have the opposite relationship to context than predicted by the weight-change model. The significant positive path coefficients between this measure and the choice measures provide some validation that rated importance is measuring weight. The lack of any significant direct paths from the choice on contextual trials to choice on the target trial indicates no support for the response-equalization hypothesis. Finally, the significant direct path between context and choice on the target trial may be interpreted as providing support for either value-shift or value-added models.

The second aim of Experiment 2 was to determine whether on-line process measures might provide additional tests of the weight-change hypothesis. On the basis of

Table 5

Mean Frequency of Looks for Sets 1 and 2 (Experiment 2)

\begin{tabular}{|c|c|c|c|c|c|c|}
\hline \multirow[b]{3}{*}{ Dimension } & \multicolumn{3}{|c|}{ Context favors $A$} & \multicolumn{3}{|c|}{ Context favors $B$} \\
\hline & \multicolumn{2}{|c|}{ Alternative } & \multirow[b]{2}{*}{ Sum } & \multicolumn{2}{|c|}{ Alternative } & \multirow[b]{2}{*}{ Sum } \\
\hline & $A$ & $B$ & & $A$ & $B$ & \\
\hline \multicolumn{7}{|c|}{ Set 1} \\
\hline \multicolumn{7}{|l|}{1} \\
\hline$M$ & 2.154 & 2.039 & 4.193 & 2.093 & 1.948 & 4.041 \\
\hline$S E$ & 0.097 & 0.097 & & 0.095 & 0.095 & \\
\hline \multicolumn{7}{|l|}{2} \\
\hline$M$ & 1.682 & 1.622 & 3.304 & 1.958 & 1.870 & 3.828 \\
\hline$S E$ & 0.094 & 0.086 & & 0.092 & 0.084 & \\
\hline Sum & 3.836 & 3.661 & 7.497 & 4.051 & 3.818 & 7.869 \\
\hline \multicolumn{7}{|c|}{ Set 2} \\
\hline \multicolumn{7}{|l|}{1} \\
\hline$M$ & 2.010 & 1.775 & 3.785 & 2.221 & 2.023 & 4.244 \\
\hline$S E$ & 0.105 & 0.098 & & 0.107 & 0.100 & \\
\hline \multicolumn{7}{|l|}{2} \\
\hline$M$ & 1.948 & 1.735 & 3.683 & 1.724 & 1.669 & 3.393 \\
\hline$S E$ & 0.106 & 0.090 & & 0.109 & 0.092 & \\
\hline Sum & 3.958 & 3.510 & 7.468 & 3.945 & 3.692 & 7.637 \\
\hline
\end{tabular}


Table 6

Correlation Matrix for Sets 1 and 2 (Experiment 2)

\begin{tabular}{|c|c|c|c|c|c|c|c|}
\hline Variable & 1 & 2 & 3 & 4 & 5 & 6 & 7 \\
\hline \multicolumn{8}{|c|}{ Set 1} \\
\hline 1. Context $B$ & - & & & & & & \\
\hline 2. Weight $B$ & $-.597 * * *$ & - & & & & & \\
\hline 3. Choice 1 & $-.916 * * *$ & $.689 * * *$ & - & & & & \\
\hline 4. Choice 2 & $-.940 * * *$ & $.675^{* * *}$ & $.925 * * *$ & - & & & \\
\hline 5. Target $B$ & .030 & $.226^{*}$ & .051 & .083 & - & & \\
\hline 6. Time 1 vs. 2 & -.182 & $.205^{*}$ & $.219^{*}$ & .170 & -.022 & - & \\
\hline 7. Frequency 1 vs. 2 & $-.294 * *$ & $.249 *$ & $.333 * * *$ & $.291 * *$ & -.112 & $.639 * * *$ & - \\
\hline \multicolumn{8}{|c|}{ Set 2} \\
\hline 1. Context $B$ & - & & & & & & \\
\hline 2. Weight $B$ & $-.460 * * *$ & - & & & & & \\
\hline 3. Choice 1 & $-.888 * * *$ & $.564 * * *$ & - & & & & \\
\hline 4. Choice 2 & $-.903 * * *$ & $.543 * * *$ & $.919 * * *$ & - & & & \\
\hline 5. Target $B$ & $.431 * * *$ & -.036 & $-.312 * *$ & $-.289 * *$ & - & & \\
\hline 6. Time 1 vs. 2 & $.293 * *$ & -.029 & $-.279 * *$ & $-.286 * *$ & .184 & - & \\
\hline 7. Frequency 1 vs. 2 & $.335 * * *$ & -.063 & $-.348^{* * *}$ & $-.356 * * *$ & $.216^{*}$ & $.613 * * *$ & - \\
\hline
\end{tabular}

Note. $\quad N=98$. Context $B=$ context favors $B$; Weight $B=$ relative weight of attribute favoring $B$; Choice $1=$ choice of $C_{2}$ on Contextual Trial 1; Choice $2=$ choice of $C_{2}$ on Contextual Trial 2; Target $B=$ choice of $B$ on target trial.

${ }^{*} p<.05 . \quad{ }^{* *} p<.01$. $* * * p<.001$.

previous research (Wedell \& Senter, 1997), it was hypothesized that greater weight would be reflected in greater looking time and frequency of acquisition. This assumption then led to the prediction from the weight-change model that when the context favored $B$, there would be relatively greater looking time and number of looks at information on $B$ 's favored dimension, Dimension 1. This relationship was obtained for one set of data, but the opposite relationship was obtained for the other set. Correlational patterns for the process measures in the two sets were also inconsistent.

\section{Experiment 3: A Test of the Role of Dominance}

The primary focus of Experiment 3 was to provide a test between value-shift and value-added models of trade-off contrast. According to the value-shift model, extending the range on a given dimension results in the same objective difference on that dimension being coded as a smaller difference in value (see Equation 4). By reducing the difference in the attractiveness value on an alternative's poorer dimension, its attractiveness advantage on the other dimension becomes relatively greater, leading to an increase in choosing that alternative.

The value-added model asserts that rather than the attractiveness of alternative values along a dimension being affected by context, relationships between an alternative and contextual alternatives may enhance or detract from an alternative's overall value. In particular, a dominating relationship should enhance the value of the alternative, because it is clearly better than the dominated alternative. However, a dominated relationship should detract from the value of the alternative because it is clearly worse than the dominating alternative. Dominance is not a property of the isolated values but rather is a relationship between the values of different alternatives.

Assuming that dominance is the primary source for adding value in this instance, a clear implication of the value-added model is that if the asymmetric dominance relationship of the target and contextual alternatives is removed, the context effect should also disappear. In Experiments 1 and 2, the locations of the contextual alternatives were as shown in Figure 1, resulting in the favored alternative dominating two contextual alternatives and the unfavored alternative being dominated by two contextual alternatives. In Experiment 3, the locations of the contextual stimuli were changed so that alternatives on the target trial were both dominated by two contextual alternatives and dominated no contextual alternatives. This was achieved by shifting the values of the contextual stimuli up on each dimension by a constant amount. This shift resulted in a similar degree of range extension found in Experiments 1 and 2 but without the asymmetric dominance. If strong contextual effects are still observed under these conditions, they cannot be attributed to an asymmetric dominance relationship.

A secondary purpose of Experiment 3 was to gather additional process-tracing measures to determine whether stable effects of the contextual manipulation could be observed on these measures. Once again, the focus for these measures was on the relationship between looking time and weight.

\section{Method}

Participants were 143 undergraduates from the University of South Carolina who received course credit for their participation. 
The design was the same as that used in Experiment 2 except that the stimulus sets were constructed so that each alternative on the target trial was dominated by two alternatives from the previous two trials.

The target alternatives $A$ and $B$ were left unchanged. Contextual stimuli were altered so that on each contextual trial, one stimulus $\left(C_{1}\right)$ dominated alternative $A$ of the target trial and one stimulus $\left(C_{2}\right)$ dominated alternative $B$ of the target trial. This was achieved by increasing (or decreasing for negatively defined dimensions such as price) the values of contextual stimuli by a constant on a given dimension. (The values for these contextual alternatives are shown in Tables A1 and A2 of the Appendix.) In all other respects, the procedure was exactly the same as that of Experiment 2.

\section{Results}

Tests for context effects on choice. Table 7 presents the choice proportions and mean dimensional importance ratings for Sets 1 and 2 . The results replicated those of Experiment 2 except that the contextual manipulation significantly affected choice on the target trial for both Sets 1 and 2 . The significantly greater subjective weight attributed to the dimension on which the favored alternative was poorest was once again inconsistent with the weight-change hypothesis. That strong and significant contextual effects were found on the target trial when the contextual alternatives dominated both targets indicates that dominance valuing is not the critical process producing trade-off contrast effects.

Process-tracing measures. Three-way repeated measures ANOVAs were conducted on the looking-time and number-of-looks data for each set. All four of these analyses produced a main effect of dimension ( $p$ s $<.001$ ), reflecting the greater time spent and the greater number of looks given to the first dimension. This is presumably an artifact of the display, in which the first dimension was always the top line of information. Unlike Experiment 2 in which three of the four Dimension $\times$ Context interactions were significant, there were no significant interactions between dimension and context in Experiment 3. The only significant interactions involving context were the Context $\times$ Alternative interactions for frequency of looks in both Sets 1 and 2 ( $p s<.05$ ). For both sets, the relative number of looks given

Table 7

Choice and Rating Data for Sets 1 and 2 (Experiment 3)

\begin{tabular}{|c|c|c|c|c|}
\hline \multirow{2}{*}{$\begin{array}{l}\text { Favored } \\
\text { alternative }\end{array}$} & \multicolumn{3}{|c|}{ Proportion choosing $C_{2}$ or $B$} & \multirow{2}{*}{$\begin{array}{c}\text { Relative } \\
\text { weight } \\
\text { Dimension 1 }\end{array}$} \\
\hline & Trial 1 & Trial 2 & Trial 3 & \\
\hline \multicolumn{5}{|c|}{ Set 1} \\
\hline $\begin{array}{l}A \\
B\end{array}$ & $\begin{array}{l}.745 \\
.252\end{array}$ & $\begin{array}{l}.689 \\
.266\end{array}$ & $\begin{array}{l}.340 \\
.500\end{array}$ & $\begin{array}{r}1.703 \\
-0.350\end{array}$ \\
\hline Difference & $.493 * * *$ & $.423 * * *$ & $-.160 * * *$ & $2.053 * * *$ \\
\hline \multicolumn{5}{|c|}{ Set 2} \\
\hline $\begin{array}{l}A \\
B\end{array}$ & $\begin{array}{l}.687 \\
.230\end{array}$ & $\begin{array}{l}.672 \\
.191\end{array}$ & $\begin{array}{l}.261 \\
.324\end{array}$ & $\begin{array}{r}1.471 \\
-1.015\end{array}$ \\
\hline Difference & $.457 * * *$ & $.481 * * *$ & $-.063 * *$ & $2.486 * * *$ \\
\hline
\end{tabular}

Note. $N=143$.

$*^{* *} p<.01 . \quad * * * p<.001$. to an alternative increased when that alternative was favored by the context. This interaction was not significant in any of the analyses of Experiment 2.

Path modeling. Table 8 presents the correlation matrices that served as the basis for path modeling. The patterns of correlations for the first five variables were similar to those found in Experiments 1 and 2. The same path model described in Figure 4 was fit to these data. For both Sets 1 and 2, the model fit, $\chi^{2}(2, N=98)=3.35, p=.19$ and $\chi^{2}(2$, $N=98)=0.81, p=.66$, respectively. All paths were significant at $p<.05$. Note that given the low values of the chi-squares, it is not possible to add a path that would significantly increase the fit of the model. Thus, Experiment 3 provides a third and fourth confirmation of the basic model shown in Figure 4. This model is inconsistent with weightchange and response-equalization models of trade-off contrast.

Unlike the correlations of Experiment 2, the dimensionwise process measures in Experiment 3 did not significantly correlate with context. Indeed, of the 11 correlations involving these measures, only 3 were statistically significant in Set 1 and 2 were statistically significant in Set 2 .

\section{Discussion}

The major finding of Experiment 3 was that trade-off contrast effects remain strong even when asymmetric dominance relationships between contextual alternatives and target alternatives are removed. This result is consistent with a value-shift interpretation of the effects of widening the range of variation along a dimension in a pairwise choice task. According to this model, the difference in the attractiveness values of target alternatives was reduced when the range was widened, thus favoring the alternative with the higher attractiveness on the other dimension. The value-shift model has also been clearly supported by work that used ratings of attractiveness of alternatives presented one at a time rather than choice between pairs of alternatives (Mellers \& Cooke, 1994). Although asymmetric dominance may add to the effect of the range manipulation, results of Experiment 3 indicate that it is clearly not necessary for the effect to occur.

The process-tracing results of Experiment 3 are inconsistent with those of Experiment 2 and show little relation to relevant measures. As such the process-tracing approach does not contribute to the understanding of choice behavior in the current experimental paradigm. The inconsistent results for the process-tracing measures are curious given the very robust positive relationship between weighting and looking-time measures found by Wedell and Senter (1997). One explanation of this difference is based on a major methodological difference between the two sets of studies. In Experiments 2 and 3, 16 different domains were used, with only 3 trials per domain. In the Wedell and Senter (1997) choice experiments, a single domain was used, with results based on between 100 and 200 trials. It is reasonable to assume that during early trials, participants' looking behavior reflects the process of getting familiar with the choice domain, range of values, and the nature of alterna- 
Table 8

Correlation Matrix for Sets 1 and 2 (Experiment 3)

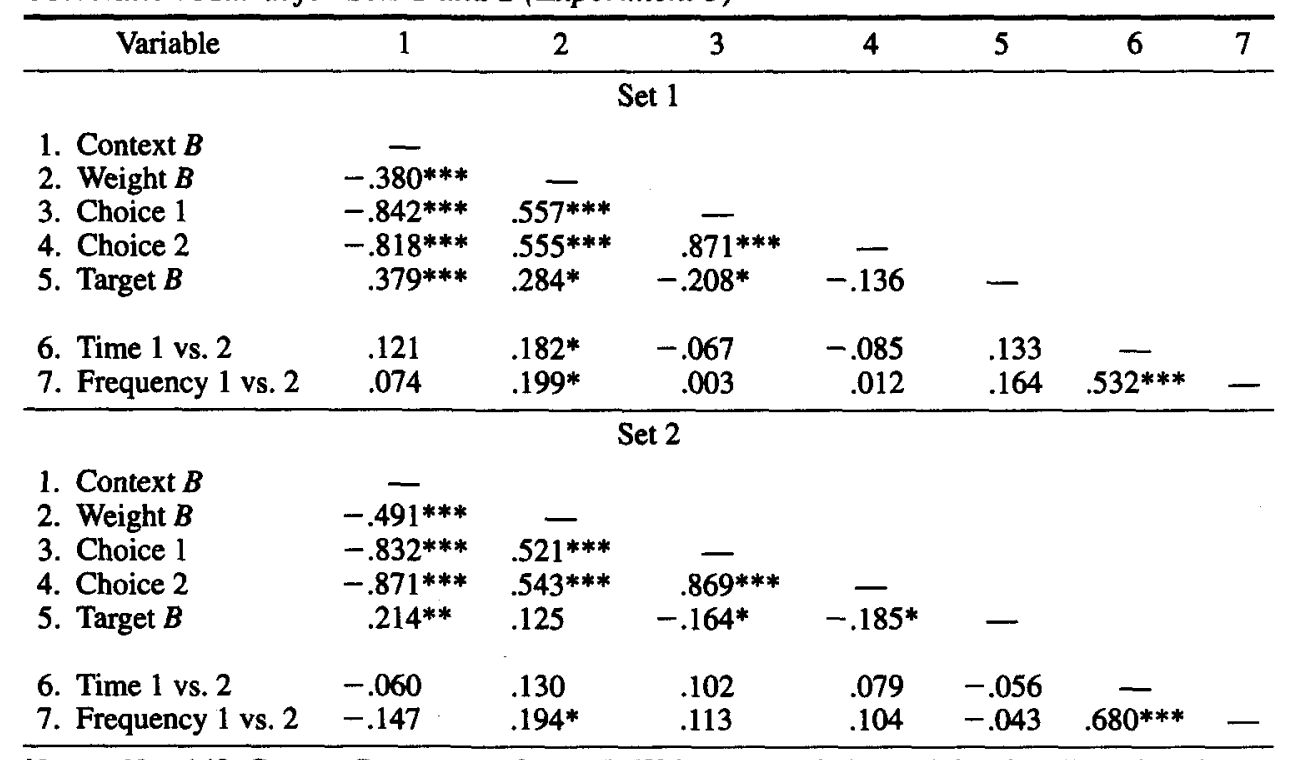

Note. $\quad N=143$. Context $B=$ context favors $B$; Weight $B=$ relative weight of attribute favoring $B$; Choice 1 = choice of $C_{2}$ on Contextual Trial 1; Choice $2=$ choice of $C_{2}$ on Contextual Trial 2; Target $B=$ choice of $B$ on target trial.

${ }^{*} p<.05 . \quad{ }^{* *} p<.01 . \quad * * * p<.001$.

tives. Looking behavior related to these processes may then obscure the relationship between weight and looking behavior that emerges when averaging across a large number of trials.

\section{General Discussion}

One of the most interesting and conflict-filled facets of choice involves the trade-offs one must make (Einhorn \& Hogarth, 1981). The research presented here replicates previous results that indicated the important role of context in making such trade-offs (Mellers \& Cooke, 1994, 1996; Simonson \& Tversky, 1992). It extends that research by outlining four plausible models by which trade-off contrast effects could operate and providing tests between these models. Consistent with research on judgment (Mellers \& Cooke, 1994), the combined results of these three experiments support a value-shift interpretation of trade-off contrast. The values presented on previous choice trials are used as a basis of comparison for evaluating current alternatives. Consistent with Parducci's $(1965,1983)$ range-frequency theory, extending the range of values on a dimension is assumed to reduce the subjective differences for any given pair of values along that dimension.

These results may be added to a growing body of research that indicates context can often affect the implicit scaling of dimensional values, which are later combined (Wedell, 1994) or used in comparative processes (Marks, 1991, 1992; Mellers, 1983, 1986; Sailor \& Pineda, 1993; Wedell, 1995, 1996). Although there is now substantial evidence for contextually based implicit scaling of values for use in cognitive operations, it should not be assumed that this type of contextual valuation will always occur in these cases. For example, Mellers and Birnbaum (1983) found no evidence that hypothetical test scores were contextually valued prior to being combined for judgments of performance, although they did find large contextual effects on the combined values of the test scores. Similarly, Wedell (1994) found evidence of individual differences in whether trait adjectives were contextually valued prior to being combined or after they were combined in an impression formation task. In judgments of differences, Mellers and Birnbaum (1982) found evidence that judgments of differences between simultaneously presented dot patterns were not contextually based. Wedell (1996) replicated this finding but also showed that introducing a short delay between presentation of members of a pair of dot patterns to be judged or having participants rate the dot patterns in a prior task resulted in dissimilarity judgments based on contextually altered implicit scale values. Mellers and Birnbaum (1982) have also shown that cross-modality matching is based on comparison of contextdependent values. Although complex, a picture is emerging concerning when context will affect implicit values on which other processes such as dissimilarity judgments or choices are based. In particular, when task or stimulus factors encourage the decision maker to construct values for stimuli rather than simply retrieve preexisting values, the constructed values are likely to be context dependent. More work is needed, but the emerging picture is that context can have pervasive effects on values used in other cognitive operations.

Three more general aspects of the research presented here are of particular note. First, the research focus was heavily 
dependent on structural equations modeling or path analysis. This technique requires the measurement of multiple dependent variables. By examining how these measures interrelate, it is possible to test between models that predict the same pattern of effects for a single dependent variable, such as choice on a target trial. Path modeling has generally been used for correlational studies. However, experimental studies with multiple dependent measures, such as the ones presented here, may also be subjected to path modeling. The major advantage is that path modeling presents a powerful tool for representing and testing different theoretical models of a given effect.

Second, this research used multiple types of measures. These included subjective ratings, prior choices, and processtracing measures. Not all of these measures were successful in providing insights into the models being tested. In particular, the mixed results of the process measures were difficult to interpret. A failure to examine the choice process from multiple perspectives, however, makes it difficult to test between competing explanations of effects on choice.

Finally, this research used multiple sets of stimuli and included multiple replications. The rather low stability of context effects for a given stimulus set is rather disconcerting. For example, the stimulus sets for which large context effects were found in Experiment 1 produced small context effects in Experiment 2. Those that produced the largest effects in Experiment 2 produced the smallest effects in Experiment 3. When choice domains were averaged across, the effects of context were very stable. This can be noted in the replicated pattern of correlations for the five primary variables, which were fit by the same path model five different times. These results, however, call into question effects observed when just one or a few choice sets are used. The use of a limited number of choice domains implies a stability of effects for a given domain that was not evident in the three experiments presented here. Thus, it seems important that future research on context effects in choice use a wide variety of choice sets.

\section{References}

Anderson, N. H. (1981). Foundations of information integration theory. New York: Academic Press.

Einhorn, H. J., \& Hogarth, R. M. (1981). Behavioral decision theory: Processes of judgment and choice. Annual Review of Psychology, 32, 53-88.

Fischer, G. W. (1995). Range sensitivity of attribute weights in multiattribute value models. Organizational Behavior and $\mathrm{Hu}$ man Decision Processes, 62, 252-266.

Goldstein, W. M. (1990). Judgments of relative importance in decision making: Global vs. local interpretations of subjective weight. Organizational Behavior and Human Decision Processes, 47, 313-336.

Gravetter, F., \& Lockhead, G. R. (1973). Criterial range as a frame of reference for stimulus judgment. Psychological Review, 80 , 203-216.

Lockhead, G. R., \& Hinson, J. (1986). Range and sequence effects in judgment. Perception \& Psychophysics, 40, 53-61.

Luce, R. D., \& Galanter, E. (1963). Psychophysical scaling. In R. D. Luce, R. R. Bush, \& E. Galanter (Eds.), Handbook of mathematical psychology (Vol. 1, pp. 245-307). New York: Wiley.

Marks, L. E. (1991). The slippery context effect in psychophysics: Intensive, extensive, and qualitative continua. Perception \& Psychophysics, 51, 187-198.

Marks, L. E. (1992). The contingency of perceptual processing: Context modifies equal-loudness relations. Psychological Science, 3, 285-291.

McArdle, J. J. (1996). Current directions in structural factor analysis. Current Directions in Psychological Science, 5, 11-18.

Mellers, B. A. (1983). Equity judgment: A revision of Aristotelian views. Journal of Experimental Psychology: General, 111, 242-270.

Mellers, B. A. (1986). "Fair" allocations of salaries and taxes. Journal of Experimental Psychology: Human Perception and Performance, 12, 80-91.

Mellers, B. A., \& Birnbaum, M. H. (1982). Loci of contextual effects in judgment. Journal of Experimental Psychology: Human Perception and Performance, 8, 582-601.

Mellers, B. A., \& Birnbaum, M. H. (1983). Contextual effects in social judgment. Journal of Experimental Social Psychology, 19, 157-171.

Mellers, B. A., \& Cooke, A. D. J. (1994). Trade-offs depend on attribute range. Journal of Experimental Psychology: Human Perception and Performance, 20, 1055-1067.

Mellers, B. A., \& Cooke, A. D. J. (1996). The role of task and context in preference measurement. Psychological Science, 7 , $76-82$.

Nosofsky, R. M. (1992). Exemplar-based approach to relating categorization, identification, and recognition. In F. G. Ashby (Ed.), Multidimensional models of perception and cognition (pp. 363-393). Hillsdale, NJ: Erlbaum.

Parducci, A. (1965). Category judgment: A range-frequency model. Psychological Review, 72, 407-418.

Parducci, A. (1974). Contextual effects: A range-frequency analysis. In E. C. Carterette \& M. P. Friedman (Eds.), Handbook of perception (Vol. 2, pp. 127-141). New York: Academic Press.

Parducci, A. (1983). Category ratings and the relational character of judgment. In H. G. Geissler, H. F. J. M. Buffort, E. L. J. Leeuwenberg, \& V. Sarris (Eds.), Modern issues in perception (pp. 89-105). Berlin, Germany: VEB Deutscher Verlag der Vissenschaffen.

Parducci, A., \& Perrett, L. F. (1971). Category rating scales: Effects of relative spacing and frequency. Journal of Experimental Psychology Monograph, 89, 427-452.

Payne, J. W., Bettman, J. R., \& Johnson, E. J. (1992). Behavioral decision research: A constructive processing perspective. Annual Review of Psychology, 43, 87-131.

Petrusic, W. M. (1992). Semantic congruity effects and theories of the comparison process. Journal of Experimental Psychology. Human Perception and Performance, 18, 962-986.

Sailor, K. M., \& Pineda, K. M. (1993). Evidence for implicit scaling in comparative judgment. Memory \& Cognition, 21, 431-439.

Shafir, E. (1993). Choosing versus rejecting: Why some options are both better and worse than others. Memory \& Cognition, 21, 546-556.

Shafir, E., Simonson, I., \& Tversky, A. (1993). Reason-based choice. Cognition, 49, 11-36.

Simonson, I. (1989). Choice based on reasons: The case of attraction and compromise effects. Journal of Consumer Research, 16, 158-174.

Simonson, I., \& Tversky, A. (1992). Choice in context: Tradeoff contrast and extremeness aversion. Journal of Marketing $\mathbf{R e}$ search, 29, 281-295. 
Steiger, J. H. (1989). Causal modeling: A supplementary module for SYSTAT and SYGRAPH. Evanston, IL: SYSTAT.

Tversky, A. (1969). Intransitivity of preferences. Psychological Review, 76, 31-48.

Tversky, A., \& Simonson, I. (1993). Context-dependent preferences. Management Science, 39, 1179-1189.

von Nitzsch, R., \& Weber, M. (1993). The effect of attribute ranges on weights in multiattribute utility measurements. Management Science, 39, 937-943.

Von Winterfeldt, D., \& Edwards, W. (1986). Decision analysis and behavioral research. Cambridge, England: Cambridge University Press.

Wedell, D. H. (1991). Distinguishing among models of contextually induced preference reversals. Journal of Experimental Psychology: Learning, Memory, and Cognition, 17, 767-778.

Wedell, D. H. (1994). Contextual contrast in evaluative judgments:
Test of pre- versus postintegration models of contrast. Journal of Personality and Social Psychology, 66, 1007-1019.

Wedell, D. H. (1995). Contrast effects in paired comparisons: Evidence for both stimulus and response based processes. Journal of Experimental Psychology: Human Perception and Performance, 21, 1158-1173.

Wedell, D. H. (1996). A constructive-associative model of the contextual dependence of unidimensional similarity. Journal of Experimental Psychology: Human Perception and Performance, $22,634-661$.

Wedell, D. H., \& Pettibone, J. C. (1996). Using judgments to understand decoy effects in choice. Organizational Behavior and Human Decision Processes, 67, 326-344.

Wedell, D. H., \& Senter, S. M. (1997). Looking and weighting in judgment and choice. Organizational Behavior and Human Decision Processes, 70, 41-64.

\title{
Appendix
}

\author{
Stimulus Materials
}

Table A1

Stimulus Materials Used in Experiments 1 and 2

\begin{tabular}{|c|c|c|c|c|c|c|c|c|c|c|}
\hline \multirow[b]{2}{*}{ Domain \& dimension } & \multicolumn{2}{|c|}{ Target } & \multicolumn{4}{|c|}{ Context favors $A$} & \multicolumn{4}{|c|}{ Context favors $B$} \\
\hline & $A$ & $B$ & $C_{1}$ & $C_{1^{\prime}}$ & $C_{2}$ & $C_{2}^{\prime}$ & $C_{1}$ & $C_{1^{\prime}}$ & $C_{2}$ & $C_{2}$ \\
\hline \multicolumn{11}{|l|}{ 1. Renting an apartment } \\
\hline Rent/person (\$) & 200 & 150 & 210 & 215 & 140 & 135 & 190 & 195 & 160 & 155 \\
\hline Min from campus & 10 & 30 & 15 & 12 & 25 & 28 & 5 & 3 & 35 & 37 \\
\hline \multicolumn{11}{|l|}{ 2. Buying a computer } \\
\hline Speed $(\mathrm{MHz})$ & 40 & 66 & 25 & 30 & 90 & 85 & 45 & 43 & 60 & 56 \\
\hline Storage capacity (megabytes) & 420 & 300 & 400 & 380 & 310 & 320 & 525 & 550 & 250 & 180 \\
\hline \multicolumn{11}{|l|}{ 3. Buying a car } \\
\hline Highway-rated gas mileage & 22 & 35 & 19 & 15 & 38 & 42 & 24 & 23 & 33 & 34 \\
\hline No. of safety features & 12 & 6 & 10 & 11 & 6 & 5 & 14 & 15 & 2 & 1 \\
\hline \multicolumn{11}{|l|}{ 4. Going to a restaurant } \\
\hline Dinner for $2(\$)$ & 50 & 30 & 60 & 65 & 25 & 20 & 43 & 47 & 40 & 35 \\
\hline Time to wait before eating (min) & 10 & 45 & 18 & 13 & 35 & 40 & 8 & 5 & 50 & 55 \\
\hline \multicolumn{11}{|l|}{ 5. Buying a plane ticket } \\
\hline Cost of ticket (\$) & 450 & 300 & 500 & 550 & 270 & 280 & 400 & 425 & 330 & 320 \\
\hline Layover time (min) & 30 & 180 & 40 & 35 & 160 & 170 & 25 & 20 & 200 & 210 \\
\hline \multicolumn{11}{|l|}{ 6. Choosing a boat } \\
\hline No. of persons & 5 & 11 & 4 & 2 & 12 & 13 & 6 & 8 & 9 & 10 \\
\hline Speed (knots/hr) & 30 & 15 & 20 & 25 & 18 & 9 & 35 & 40 & 10 & 12 \\
\hline \multicolumn{11}{|l|}{ 7. Hiring a mechanic } \\
\hline Warranty on labor (days) & 30 & 60 & 21 & 7 & 75 & 90 & 45 & 40 & 55 & 50 \\
\hline Experience (years) & 15 & 7 & 12 & 13 & 11 & 9 & 20 & 19 & 3 & 5 \\
\hline \multicolumn{11}{|l|}{ 8. Buying a $\mathrm{CD}$ player } \\
\hline Price (\$) & 250 & 175 & 260 & 265 & 140 & 155 & 240 & 235 & 180 & 195 \\
\hline No. of discs it plays & 10 & 4 & 8 & 6 & 6 & 5 & 13 & 15 & 3 & 1 \\
\hline \multicolumn{11}{|l|}{ 9. Choosing between job offers } \\
\hline Hr worked/week & 40 & 30 & 45 & 50 & 25 & 22 & 30 & 35 & 32 & 34 \\
\hline No. of paid holidays/years (days) & 14 & 8 & 12 & 13 & 10 & 9 & 15 & 16 & 6 & 5 \\
\hline \multicolumn{11}{|l|}{ 10. Buying a house } \\
\hline Price (thousands of \$) & 65 & 40 & 71 & 75 & 38 & 36 & 54 & 58 & 48 & 43 \\
\hline No. of $\mathrm{ft}^{2}$ & 1,500 & 900 & 1,350 & 1,300 & 1,200 & 1,100 & 1,600 & 1,650 & 800 & 750 \\
\hline \multicolumn{11}{|l|}{ 11. Buying an electric keyboard } \\
\hline Tone quality rating $(0-100)$ & 75 & 85 & 70 & 65 & 90 & 94 & 78 & 81 & 82 & 83 \\
\hline No. of features & 20 & 10 & 17 & 18 & 13 & 12 & 25 & 26 & 8 & 5 \\
\hline \multicolumn{11}{|l|}{ 12. Buying a mini-LCD TV } \\
\hline Price (\$) & 195 & 100 & 225 & 250 & 85 & 80 & 180 & 185 & 115 & 125 \\
\hline Distortion (\%) & 2 & 4 & 2.9 & 2.5 & 3.5 & 3.2 & 1.5 & 1 & 4.5 & 5 \\
\hline
\end{tabular}


Table A1 (continued)

Stimulus Materials Used in Experiments 1 and 2

\begin{tabular}{|c|c|c|c|c|c|c|c|c|c|c|}
\hline \multirow[b]{2}{*}{ Domain \& dimension } & \multicolumn{2}{|c|}{ Target } & \multicolumn{4}{|c|}{ Context favors $A$} & \multicolumn{4}{|c|}{ Context favors $B$} \\
\hline & $A$ & $B$ & $C_{1}$ & $c_{1}^{\prime}$ & $C_{2}$ & $C_{2^{\prime}}$ & $C_{1}$ & $c_{1^{\prime}}$ & $\overline{C_{2}}$ & $C_{2^{\prime}}$ \\
\hline \multicolumn{11}{|l|}{ 13. Choosing a preschool } \\
\hline No. of children/class & 13 & 8 & 17 & 18 & 7 & 6 & 12 & 11 & 9 & 10 \\
\hline Experience of teacher (years) & 12 & 4 & 10 & 9 & 6 & 5 & 15 & 17 & 1 & 2 \\
\hline \multicolumn{11}{|l|}{ 14. Buying a microwave } \\
\hline Warranty (months) & 6 & 18 & 3 & 1 & 24 & 36 & 9 & 12 & 12 & 15 \\
\hline Power (W) & 1,500 & 1,000 & 1,450 & 1,400 & 1,200 & 1,250 & 1,600 & 1,700 & 800 & 900 \\
\hline \multicolumn{11}{|l|}{ 15. Buying a parking space } \\
\hline Price/month (\$) & 35 & 25 & 40 & 45 & 12 & 15 & 32 & 30 & 29 & 27 \\
\hline Distance to residence (blocks) & 3 & 9 & 5 & 4 & 8 & 6 & 2 & 1 & 12 & 15 \\
\hline \multicolumn{11}{|l|}{ 16. Buying a video camera } \\
\hline Weight (lb) & 6.2 & 4.3 & 6.9 & 7.5 & 4 & 3.8 & 5.9 & 5.5 & 4.8 & 5.1 \\
\hline No. of features & 13 & 4 & 10 & 12 & 7 & 6 & 17 & 16 & 1 & 2 \\
\hline
\end{tabular}

Note. $C_{1}$ and $C_{2}$ were presented on Trial $1 ; C_{1^{\prime}}$ and $C_{2^{\prime}}$ were presented on Trial $2 ; A$ and $B$ were presented on Trial 3, the target trial. $\mathrm{CD}=$ compact disc.

Table A2

Stimulus Materials Used in Experiment 3

\begin{tabular}{|c|c|c|c|c|c|c|c|c|c|c|}
\hline \multirow[b]{2}{*}{ Domain \& dimension } & \multicolumn{2}{|c|}{ Target } & \multicolumn{4}{|c|}{ Context favors $A$} & \multicolumn{4}{|c|}{ Context favors $B$} \\
\hline & $\boldsymbol{A}$ & $B$ & $C_{1}$ & $C_{1^{\prime}}$ & $C_{2}$ & $C_{2}^{\prime}$ & $C_{1}$ & $C_{1}$ & $C_{2}$ & $C_{2^{\prime}}$ \\
\hline \multicolumn{11}{|l|}{ 1. Renting an apartment } \\
\hline Rent/person (\$) & 200 & 150 & 198 & 197 & 128 & 117 & 178 & 187 & 148 & 147 \\
\hline Min from campus & 10 & 30 & 9 & 8 & 19 & 24 & 1 & 1 & 27 & 26 \\
\hline \multicolumn{11}{|l|}{ 2. Buying a computer } \\
\hline Speed $(\mathrm{MHz})$ & 40 & 66 & 42 & 44 & 107 & 99 & 53 & 56 & 68 & 69 \\
\hline Storage capacity (megabytes) & 420 & 300 & 422 & 423 & 332 & 363 & 577 & 674 & 302 & 304 \\
\hline \multicolumn{11}{|l|}{ 3. Buying a car } \\
\hline Highway-rated gas mileage & 22 & 35 & 23 & 24 & 42 & 51 & 27 & 26 & 36 & 37 \\
\hline No. of safety features & 12 & 6 & 13 & 14 & 9 & 8 & 17 & 21 & 5 & 7 \\
\hline \multicolumn{11}{|l|}{ 4. Going to a restaurant } \\
\hline Dinner for $2(\$)$ & 50 & 30 & 48 & 47 & 13 & 2 & 31 & 38 & 28 & 26 \\
\hline Time to wait before eating ( $\mathrm{min}$ ) & 10 & 45 & 9 & 8 & 26 & 35 & 1 & 0 & 43 & 42 \\
\hline \multicolumn{11}{|l|}{ 5. Buying a plane ticket } \\
\hline Cost of ticket $(\$)$ & 450 & 300 & 448 & 446 & 218 & 176 & 369 & 402 & 299 & 297 \\
\hline Layover time (min) & 30 & 180 & 28 & 27 & 148 & 162 & 10 & 10 & 178 & 176 \\
\hline \multicolumn{11}{|l|}{ 6. Choosing a boat } \\
\hline No. of persons & 5 & 11 & 6 & 7 & 14 & 18 & 9 & 12 & 12 & 16 \\
\hline Speed (knots/hr) & 30 & 15 & 33 & 34 & 31 & 28 & 41 & 46 & 14 & 18 \\
\hline \multicolumn{11}{|l|}{ 7. Hiring a mechanic } \\
\hline Warranty on labor (days) & 30 & 60 & 32 & 34 & 86 & 117 & 51 & 54 & 61 & 64 \\
\hline Experience (years) & 15 & 7 & 17 & 18 & 16 & 14 & 25 & 23 & 8 & $: 9$ \\
\hline \multicolumn{11}{|l|}{ 8. Buying a $C D$ player } \\
\hline Price (\$) & 250 & 175 & 249 & 247 & 129 & 137 & 234 & 213 & 174 & 173 \\
\hline No. of discs it plays & 10 & 4 & 11 & 12 & 9 & 11 & 15 & 21 & 5 & 7 \\
\hline \multicolumn{11}{|l|}{ 9. Choosing between job offers } \\
\hline Hr worked/week & 40 & 30 & 38 & 37 & 19 & 9 & 27 & 29 & 29 & 28 \\
\hline No. of paid holidays/year (days) & 14 & 8 & 15 & 16 & 13 & 12 & 18 & 21 & 9 & 10 \\
\hline \multicolumn{11}{|l|}{ 10. Buying a house } \\
\hline Price (thousands of \$) & 65 & 40 & 64 & 63 & 31 & 24 & 45 & 53 & 39 & 38 \\
\hline No. of $\mathrm{ft}^{2}$ & 1,500 & 900 & 1,510 & 1,520 & 1,360 & 1,320 & 1,710 & 1,815 & 910 & 915 \\
\hline \multicolumn{11}{|l|}{ 11. Buying an electric keyboard } \\
\hline Tone quality rating $(0-100)$ & 75 & 85 & 77 & 79 & 97 & 100 & 83 & 87 & 87 & 89 \\
\hline No. of features & 20 & 10 & 21 & 23 & 17 & 17 & 29 & 34 & 12 & 13 \\
\hline \multicolumn{11}{|l|}{ 12. Buying a mini-LCD TV } \\
\hline Price (\$) & 195 & 100 & 194 & 192 & 54 & 22 & 163 & 157 & 98 & 97 \\
\hline Distortion (\%) & 2 & 4 & 1.98 & 1.96 & 1.99 & 1.97 & 3.95 & 3.92 & 3.98 & 3.96 \\
\hline \multicolumn{11}{|l|}{ 13. Choosing a preschool } \\
\hline No. of children/class & 13 & 8 & 12 & 11 & 2 & 1 & 10 & 7 & 7 & 6 \\
\hline Experience of teacher (years) & 12 & 4 & 12 & 14 & 10 & 12 & 19 & 21 & 5 & 6 \\
\hline
\end{tabular}


Table A2 (continued)

Stimulus Materials Used in Experiment 3

\begin{tabular}{|c|c|c|c|c|c|c|c|c|c|c|c|}
\hline \multirow[t]{2}{*}{. } & \multirow[b]{2}{*}{ Domain \& dimension } & \multicolumn{2}{|c|}{ Target } & \multicolumn{4}{|c|}{ Context favors $A$} & \multicolumn{4}{|c|}{ Context favors $B$} \\
\hline & & $A$ & $B$ & $C_{1}$ & $C_{1}$ & $C_{2}$ & $C_{2^{\prime}}$ & $C_{1}$ & $C_{1}$ & $C_{2}$ & $C_{2}$ \\
\hline \multicolumn{12}{|c|}{ 14. Buying a microwave } \\
\hline & Warranty (months) & 6 & 18 & 7 & 9 & 28 & 44 & 16 & 17 & 19 & 20 \\
\hline & Power (W) & 1,500 & 1,000 & 1,504 & 1,505 & 1,254 & 1,355 & 1,805 & 1,807 & 1,005 & 1,007 \\
\hline \multicolumn{12}{|c|}{ 15. Buying a parking space } \\
\hline & Price/month (\$) & 35 & 25 & 34 & 32 & 6 & 2 & 26 & 25 & 23 & 22 \\
\hline & Distance to residence (blocks) & 3 & 9 & 2 & 1 & 5 & 3 & 1 & 1 & 8 & 7 \\
\hline \multicolumn{12}{|c|}{ 16. Buying a video camera } \\
\hline & Weight (b) & 6.2 & 4.3 & 6.1 & 6.0 & 3.2 & 2.3 & 5.3 & 4.5 & 4.2 & 4.1 \\
\hline & No. of features & 13 & 4 & 14 & 15 & 11 & 9 & 21 & 21 & 5 & 7 \\
\hline
\end{tabular}

Note. $\quad C_{1}$ and $C_{2}$ were presented on Trial $1 ; C_{1}$ and $C_{2}$, were presented on Trial 2;A and $B$ were presented on Trial 3, the target trial. CD $=$ compact disc.

Received February 5, 1996

Revision received July 17, 1996

Accepted November 12, 1996

\section{American Psychological Association SUBSCRIPTION ClaAMS INFORMATION}

Today's Date:

We provide this form to assist members, institutions, and nonmember individuals with any subscription problems. With the appropriate information we can begin a resolution. If you use the services of an agent, please doNOT duplicate claims through them and directly to us. PLEASE PRINT CLEARLY AND IN INK IF POSSIBLE.

PRINT FULL NAME OR KEY NAME OF INSTITUTION

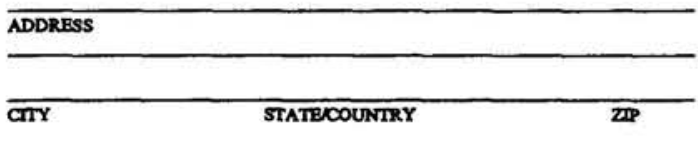

YOUR NAME AND PHONE NUMBER

TrTLE

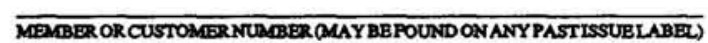

DATE YOUR ORDER WAS MAIIED (OR PHONED)

PREPAID C CHECK _CHARGE CHECKNCARD CIBARED DATE:

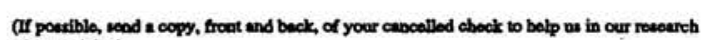
of your cletim)

VOLUMB OR YEAR

NUMBERR OR MONTH

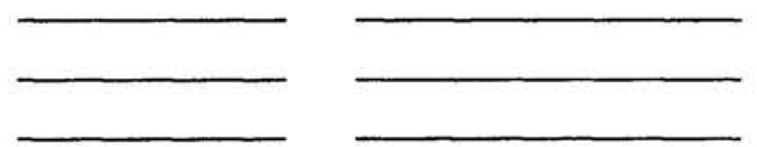

Thank you. Once a claim is received and resolved, delivery of roplacemont issues routinely takes 4 - 6 weeks. (TO BE FLLED OUT BY APA STAFF)

DATE RECETVED:

DATE OF ACTION:

ACTION TAKEN:

INV. NO. \& DATE:

STAFF NAME:

LABEL NO. \& DATE:

Send this form to APA Subscription Claims, 750 Frst Street, NE, Washmgton, DC 20002-4242

PLEASE DO NOT REMOVE. A PHOTOCOPY MAY BE USED. 